\section{Androgen-Deprivation Therapy Is More Than Palliation in Oligometastatic Prostate Cancer}

To тHE EDITOR: Ost et $\mathrm{al}^{1}$ recently reported the results of a randomized phase II study, which assessed the benefit of metastasisdirected therapy (MDT) compared with surveillance for oligorecurrent prostate cancer $(\mathrm{PCa})$. Sixty-two patients with $\mathrm{PCa}$ with a prostate-specific antigen (PSA) relapse after local treatment with curative intent and up to three extracranial metastases were randomly assigned to either surveillance or MDT. The primary end point was androgen-deprivation therapy (ADT) -free survival, defined as the time between random assignment and the start of palliative ADT or death. Mean PSA values at inclusion were $6.9 \mathrm{ng} / \mathrm{mL}$ (range, 0.3 to $31.0 \mathrm{ng} / \mathrm{mL}$ ) and $9 \mathrm{ng} / \mathrm{mL}$ (range, 0.7 to $44.5 \mathrm{ng} / \mathrm{mL}$ ) in the surveillance and MDT groups, respectively. Twenty-one patients $(33.9 \%)$ had regional node-limited disease, whereas 41 (66.1\%) showed metastatic disease. Patients treated with MDT experienced a longer ADT-free survival compared with those who underwent surveillance alone (hazard ratio, $0.60 ; 80 \% \mathrm{CI}, 0.40$ to 0.90 ; $\log$-rank $P=.11$ ); it seemed that the magnitude of benefit with MDT was greater for those patients with a shorter PSA doubling time. Safety of MDT was excellent, and quality of life was similar between arms. On the basis of these data, the authors concluded that MDT was a promising approach for oligorecurrent PCa and should be explored in larger phase III studies.

Some limitations of this trial should be underlined. First, these results are merely explorative, because the prespecified $\alpha$ and $\beta$ cutoff of 0.20 was not chosen to validate the superiority of a clinical intervention but rather to determine which arm was justified to be tested in a subsequent phase III trial; MDT improved ADT-free survival compared with surveillance without statistical significance using the standard $\alpha=0.05$ cutoff (hazard ratio, $0.60 ; 80 \% \mathrm{CI}$, 0.31 to 1.13 ; $\log$-rank $P=.11$ ). Second, it is easy to win without a competitor. ADT is actually the gold standard for patients with oligometastatic PCa, whereas surveillance or delayed ADT (control arm) is only recommended in asymptomatic patients with a strong wish to avoid treatment-related adverse effects. ${ }^{2}$ Immediate ADT should be offered as first choice of treatment to all men who experience relapse after radical treatment with curative intent, consistent with the results from the phase III TOAD (Timing of Androgen Deprivation) trial, which demonstrated a significant improvement in overall survival with immediate ADT compared with delayed intervention. ${ }^{3}$
Moreover, the results from STAMPEDE (Systemic Therapy in Advancing or Metastatic Prostate Cancer: Evaluation of Drug Efficacy) studies suggest that ADT in combination with docetaxel or abiraterone may be used for selected cases of castration-naïve oligometastatic PCa. ${ }^{4,5}$ Initial aggressive systemic approaches in oligorecurrent $\mathrm{PCa}$ may eradicate pre-existing subpopulations of resistant tumor clones, thus improving survival and preventing subsequent treatment-induced lineage crisis, which is characteristic of advanced and highly pretreated $\mathrm{PCa} .{ }^{6,7}$

Instead of surveillance, ADT or other systemic approaches should represent the control arm of such a study. ADT-free survival seems to be an inadequate end point for actual evidence, and clinicians should not be encouraged to replace immediate ADT with MDT in patients with oligometastatic PCa. MDT may be a promising approach from a multimodal perspective, and additional trials should probably investigate, in a larger sample size, the survival benefit of MDT in combination with other systemic treatments, which currently represent the standard of care.

\section{Carlo Cattrini, Elisa Zanardi, and Francesco Boccardo}

San Martino Polyclinic Hospital-Institute for Cancer Research and Treatment; and School of Medicine, University of Genoa, Genoa, Italy

\section{AUTHORS' DISCLOSURES OF POTENTIAL CONFLICTS OF INTEREST}

Disclosures provided by the authors are available with this article at jco.org.

\section{REFERENCES}

1. Ost $P$, Reynders $D$, Decaestecker $K$, et al: Surveillance or metastasisdirected therapy for oligometastatic prostate cancer recurrence: A prospective, randomized, multicenter phase II trial. J Clin Oncol 36:446-453, 2018

2. Mottet $N$, Bellmunt J, Briers $E$, et al: EAU-ESTRO-SIOG Guidelines on Prostate Cancer. https://uroweb.org/wp-content/uploads/EAU-Guidelines-ProstateCancer-2016-Pocket.pdf

3. Duchesne GM, Woo HH, Bassett JK, et al: Timing of androgen-deprivation therapy in patients with prostate cancer with a rising PSA (TROG 03.06 and VCOG PR 01-03 [TOAD]): A randomised, multicentre, non-blinded, phase 3 trial. Lancet Oncol 17:727-737, 2016

4. James ND, de Bono JS, Spears MR, et al: Abiraterone for prostate cancer not previously treated with hormone therapy. N Engl J Med 377:338-351, 2017

5. James ND, Sydes MR, Clarke NW, et al: Addition of docetaxel, zoledronic acid, or both to first-line long-term hormone therapy in prostate cancer (STAMPEDE): Survival results from an adaptive, multiarm, multistage, platform randomised controlled trial. Lancet 387:1163-1177, 2016

6. Roubaud G, Liaw BC, Oh WK, et al: Strategies to avoid treatment-induced lineage crisis in advanced prostate cancer. Nat Rev Clin Oncol 14:269-283, 2017

7. Cattrini $C$, Zanardi $E$, Vallome $G$, et al: Targeting androgen-independent pathways: New chances for patients with prostate cancer? Crit Rev Oncol Hematol 118:42-53, 2017

DOI: https://doi.org/10.1200/JCO.2018.78.0031; published at jco.org on June 1, 2018. 


\section{AUTHORS' DISCLOSURES OF POTENTIAL CONFLICTS OF INTEREST}

Androgen-Deprivation Therapy Is More Than Palliation in Oligometastatic Prostate Cancer

The following represents disclosure information provided by authors of this manuscript. All relationships are considered compensated. Relationships are self-held unless noted. I = Immediate Family Member, Inst = My Institution. Relationships may not relate to the subject matter of this manuscript. For more information about ASCO's conflict of interest policy, please refer to www.asco.org/rwc or ascopubs.org/jco/site/ifc.

\section{Carlo Cattrini}

No relationship to disclose

Elisa Zanardi

No relationship to disclose

\section{Francesco Boccardo}

No relationship to disclose 